Article

\title{
A Label-Free and Ultrasensitive Immunosensor for Detection of Human Chorionic Gonadotrophin Based on Graphene FETs
}

\author{
Kamrul Islam * (D), Ahmed Suhail and Genhua Pan \\ Wolfson Nanomaterials and Devices Laboratory, School of Computing, Electronics and Mathematics, \\ Faculty of Science and Engineering, University of Plymouth, Drake Circus, Plymouth PL4 8AA, UK; \\ ahmed.suhail@plymouth.ac.uk (A.S.); G.Pan@plymouth.ac.uk (G.P.) \\ * Correspondence: kamrul.islam@plymouth.ac.uk; Tel.: +44-1752-586282
}

Received: 1 June 2017; Accepted: 3 July 2017; Published: 12 July 2017

\begin{abstract}
We report on a label-free immunosensor based on graphene field effect transistors (G-FETs) for the ultrasensitive detection of Human Chorionic Gonadotrophin (hCG), as an indicator of pregnancy and related disorders, such as actopic pregnancy, choriocarcinoma and orchic teratoma. Pyrene based bioactive ester was non-covalently anchored onto the graphene channel in order to retain the $\mathrm{sp}^{2}$ lattice. The G-FET transfer characteristics showed repeatable and reliable responses in all surface modifying steps using a direct current (DC) readout system. The hCG concentration gradient showed a detection limit of $\sim 1 \mathrm{pg} \cdot \mathrm{mL}^{-1}$. The proposed method facilitates the cost-effective and viable production of graphene point-of-care devices for clinical diagnosis.
\end{abstract}

Keywords: graphene; field effect transistor; immunosensor; human chorionic gonadotrophin

\section{Introduction}

Human Chorionic Gonadotrophin (hCG) is a glycosylated protein (37.5 kDa) secreted by placenta during pregnancy or gestational trophoblastic diseases [1,2]. The function of hCG is to stimulate steroid hormone and progesterone production in the corpus luteum to support placental growth [3]. Hence, increased levels of hCG in the serum and urine are key indicators of trophoblastic tumors and other pregnancy related diseases [4-6]. As a result, it is significantly important to develop a highly selective and sensitive sensor to detect hCG for early diagnosis. At present, the detection methods for hCG mainly include various immunoassay based on electrochemical, electrochemiluminescence, fluorescence, enzyme, chemiluminescence resonance energy transfer, chemiluminescence and radiation [7]. Though these systems are sensitive and selective, but they tend to be expensive, time-consuming, labor intensive, bulky and require additional electrical system to translate into electrical signals. Hence, there is a need in manufacturing reliable and scalable electrical method to meet the demand for point of care testing (POCT) devices.

Since the first report by Bergveld et al. on FET based immunosensor (immunoFET), numerous studies have been conducted on immunoFET based on silicon nanowires (SiNW), $\mathrm{SiO}_{2}$ nanobelt, $\mathrm{ZnO}$ nanofilm, Au nanoparticles, molybdenum disulphide $\left(\mathrm{MoS}_{2}\right)$, cerium oxide $\left(\mathrm{CeO}_{x}\right)$ and single-walled carbon nanotubes (SWCNT) to name a few [8,9]. Recently, graphene attracted much interest by various research groups to focus on the possibility of graphene based FET (gFET) due to its unique characteristics regarding high surface to volume ratio, biocompatibility consisting of extreme sensitivity to the environment and ambipolar behavior [10-13]. Half a dozen of reports has appeared in last few years on back-gated graphene field effect transistor (BG-gFET) immunosensors, indicating that there is a growing interest from both academic and industrial researchers to meet all the challenges for cost-effective, easy to fabricate, scalable, reliable, ultrasensitive and rapid on-site 
detection devices [14-19]. Note that a non-covalent functionalization is of graphene is of much importance as covalent functionalization augments carrier scattering instigated by the conversion of planar $\mathrm{sp}^{2}$ to tetrahedral $\mathrm{sp}^{3}$ carbons leading to charge impurities and vacancy defects. To the best of our knowledge, there is only one report on BG-gFET based immunoassay for hCG detection, using multilayer epitaxial graphene grown on silicon carbide and a covalent functionalization method was used to anchor the necessary biomolecules. Other BG-gFET based immunoassays adopted intermediary modification of graphene either by hexamethyldisilazane (HMDS) or reduced to graphene oxide targeting rotavirus, DNA or cancer biomarkers [15-17].

In the present study, we demonstrate a scalable CVD grown monolayer graphene based FET immunosensor on $\mathrm{SiO}_{2} / \mathrm{Si}$ substrate. A non-covalent bond between monolayer graphene and antibody was facilitated by applying a linker molecule known as 1-pyrenebutyric acid-N-hydroxysuccinimide ester (Pyr-NHS) via $\pi-\pi$ bonding. The performance of the device was assessed under ambient conditions for over 10 devices to establish higher stability and repeatability. Changes in resistance difference between consecutive surface modifications displayed a distinctive pattern not commonly seen in relation to the usual increase in resistance owing to biomolecular absorption. The sensor exhibited an ultralow label-free detection limit of $1 \mathrm{pg} \cdot \mathrm{mL}^{-1}$ with high sensitivity $\left(0.30 \Omega \cdot \mathrm{ng}^{-1} \cdot \mathrm{mL}^{-1}\right)$ and reproducibility ( $>87 \%$ yield). An in-depth analysis on carrier transfer for each surface modification was carried out for the first time for non-covalently functionalized BG-gFET illustrating the importance of net charge, amino acid content and the isoelectric point of biomolecules. These key factors are vital for bioelectronic sensing mechanism and device performance. The rapid, sensitive, selective, stable, repeatable and reliable detection suggests promising applications of bgFET structure for multiple marker detection on a point-of-care device.

\section{Materials and Methods}

\subsection{Materials}

Monolayer CVD graphene on $\mathrm{Cu}$ foil was purchased from Graphene Supermarket (Calverton, NY, USA). Photoresist 1805 G2, lift-off resist 3B (LoR) and their corresponding developer and remover were purchased from A-Gas Electronic Materials (Warwickshire, UK). All the other chemicals, such as Pyr-NHS, iron nitride, nitric acid, PBS, Poly (methyl methacrylate) (PMMA), Ethanolamine etc. at biochemical grade were purchased from Sigma Aldrich (Dorset, UK). Bovine serum albumin (BSA) at biochemical grade was purchased from Sigma Aldrich (Dorset, UK). $100 \mu \mathrm{g} \cdot \mathrm{hCG}$ (ab126652) lyophilized powder and $1 \mathrm{~mL}$ of $0.02 \mathrm{mg} \cdot \mathrm{mL}^{-1}$ complementary anti-hCG (ab8466) in PBS buffer were purchased from Abcam (Cambridge, UK) and the prepared aliquots were stored at $-20^{\circ} \mathrm{C}$.

\subsection{Characterization of $B G-g F E T$}

Raman spectra was collected in an XploRA Raman system (Horiba, Middlesex, UK) running a LabSpec 6.4.2.5 and equipped with a $532 \mathrm{~nm}$ HeNe laser delivering $20 \mathrm{~mW}$ of laser power at the sample. An Olympus BX41 microscope (Olympus Corp., Tokyo, Japan) with a $100 \mu \mathrm{m}$ slit width, a $300 \mu \mathrm{m}$ confocal hole, $1200 \mathrm{~T}$ grating and 1000× magnification was used. An MPlan N 100× microscope objective (N.A.: 0.90, W.D.: 0.21, F.N.: 22) focused the laser on the sample into a spot of $\sim 7.45 \mu \mathrm{m}$ diameter. A thermoelectrically cooled charge coupled device (CCD) camera was used for detection. Single spectra were collected for bare, coated and non-coated dentine by graphene from $1100 \mathrm{~cm}^{-1}$ to $3000 \mathrm{~cm}^{-1}$ range with five accumulations each lasting $15 \mathrm{~s}$.

X-ray photoelectron spectroscopy (XPS) was performed with Kratos AXISULTRA with a monochromated Al $\mathrm{k} \alpha$ X-ray source $(1486.6 \mathrm{eV})$ using an emission current of $10 \mathrm{~mA}$ and an anode potential of $12 \mathrm{kV}(120 \mathrm{~W})$. The ULTRA was used in fixed analyzer transmission (FAT) mode, with pass energy of $80 \mathrm{eV}$ for wide scans and pass energy $20 \mathrm{eV}$ for high resolution scans. Cyclic Voltammetry (CV) measurements were carried out in $10 \mathrm{mM}$ ferricyanide aqueous solution ( $1 \mathrm{M} \mathrm{KCl}$ solution) at room temperature with a scan potential range from $0.8 \mathrm{~V}$ to $-0.4 \mathrm{~V}$ and a scan rate of $100 \mathrm{mV} \cdot \mathrm{s}^{-1}$. 


\subsection{Sensor Test and Data Analysis}

A Keysight B1500A semiconductor device parameter analyzer with an MPS150 probe station (Cascade Microtech $\mathrm{GmbH}$, Thiendorf, Germany) was employed to investigate the electrical characteristics and sensing performance of the FET device at room temperature. The transistor measurement on the sensor was carried out by measuring the drain current (Ids) as a function of the gate voltage $(\mathrm{Vg})(-100 \mathrm{~V}$ to $+100 \mathrm{~V})$ with a fixed drain-source voltage $(\mathrm{Vds}=100 \mathrm{mV})$. The sensing signal of the device was recorded by monitoring the Ids as a function of drain-source voltage $(\mathrm{Vd})(-1 \mathrm{~V}$ to $+1 \mathrm{~V})$ with a fixed gate voltage $(\mathrm{Vds}=0 \mathrm{~V})$. The data were analysed using SigmaPlot 13 software (Systat Software Inc, London, UK).

\subsection{Wet Transfer of Graphene}

The monolayer graphene was obtained from Graphene Supermarket (Calverton, NY, USA), and it was synthesized on both sides of $25 \mu \mathrm{m}$ thick copper foil through chemical vapour deposition (CVD) method [20]. The wet transfer process as shown in Figure 1 was used to transfer monolayer graphene onto $\mathrm{SiO}_{2} / \mathrm{Si}$ substrates as follows. Firstly, PMMA was dissolved in the chlorobenzene with a $10 \mathrm{mg} \cdot \mathrm{mL}^{-1}$ concentration and spin-coated on the one side of the graphene film at a spin speed of $4000 \mathrm{rpm}$ for $30 \mathrm{~s}$ followed by baking at $180^{\circ} \mathrm{C}$ for $1 \mathrm{~min}$. To etch the $\mathrm{Cu}$ substrate, $10 \% \mathrm{HNO}_{3}$ was used for $2 \mathrm{~min}$ followed by etching in $0.1 \mathrm{M}$ ammonium persulfate for approximately $3 \mathrm{~h}$ with the endpoint determined when $\mathrm{Cu}$ was no longer visible. The resulted PMMA/graphene membrane was transferred to a rinse bath of deionized (DI)water for $10 \mathrm{~min}$. Subsequently, monolayer graphene was directly transferred onto $\mathrm{SiO}_{2} / \mathrm{Si}$ substrates. Finally, PMMA layer was removed by acetone treatment at $50{ }^{\circ} \mathrm{C}$ for five minutes following by cleaning with Isopropyl alcohol (IPA) and DI water. Graphene on $\mathrm{SiO}_{2} / \mathrm{Si}$ substrates obtained as such was dried in vacuum before characterization and measurements.

(a)

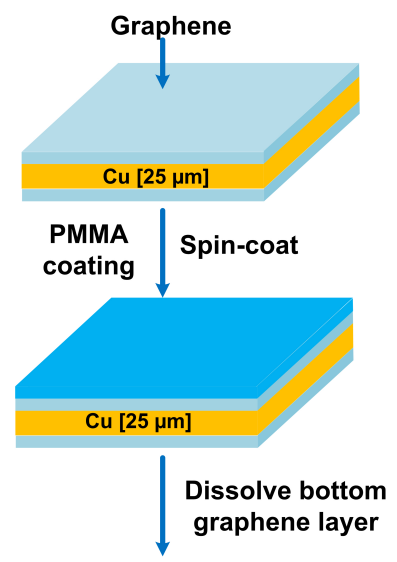

(c)

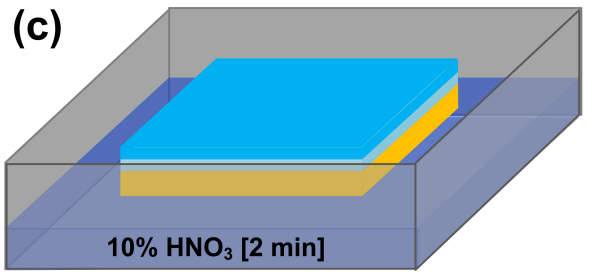

(d)

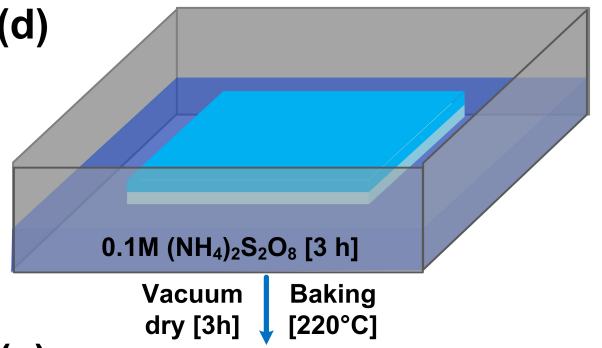

(e)

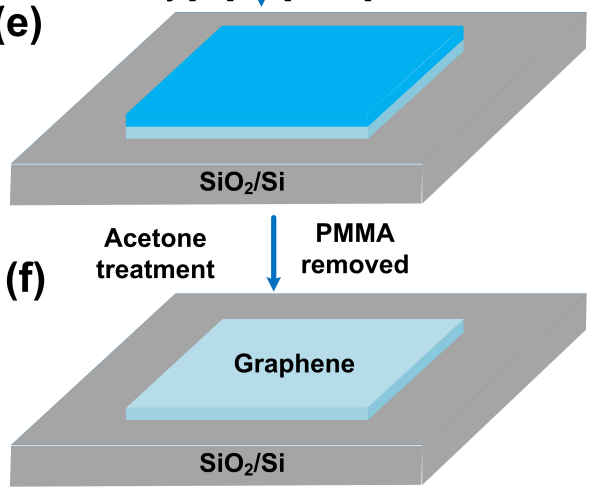

Figure 1. Schematic illustration of graphene wet transfer on $\mathrm{SiO}_{2} / \mathrm{Si}$. The process begins with a graphene monolayer on $\mathrm{Cu}$ foil (a); After depositing a support layer composed of PMMA (b); the bottom graphene layer and $\mathrm{Cu}$ layer are etched by floating the sample on a $\mathrm{HNO}_{3}$ and $\left(\mathrm{NH}_{4}\right)_{2} \mathrm{~S}_{2} \mathrm{O}_{8}$ respectively (c,d); After transferring the resulting graphene-PMMA bilayer on a $\mathrm{SiO}_{2} / \mathrm{Si}$ substrate, PMMA removal by acetone $(\mathbf{e}, \mathbf{f})$ completes the transfer process. 


\subsection{Materials Fabrication of hCG Biosensor}

A schematic illustration of the fabrication of hCG biosensor is shown in Figure 2. A flexible monolayer-layer graphene film on $\mathrm{SiO}_{2} / \mathrm{Si}$ substrate was obtained by wet-transfer method as mentioned above [21,22]. In order to fabricate source-drain and voltage electrodes, two consecutive photolithography was conducted. The lithography process begins with spin-coating LoR and positive photoresist (pPR) at $3000 \mathrm{rpm}$ for $30 \mathrm{~s}$. LoR was pre-baked at $175^{\circ} \mathrm{C}$ for $15 \mathrm{~min}$ followed by soft-baking of spin-coated pPR at $100{ }^{\circ} \mathrm{C}$ for $1 \mathrm{~min}$. For shaping graphene channel, samples were hard-baked at $180{ }^{\circ} \mathrm{C}$ for about an hour under deep UV (DUV) to reduce the pPR effect on graphene channel as much as possible [19]. We used a modified Argon plasma method to sputter the graphene on $\mathrm{SiO}{ }_{2} / \mathrm{Si}$ at $50 \mathrm{~W}$ and $6 \times 10^{-7}$ Torr for $2 \mathrm{~min}$ [23]. We deposited $5 \mathrm{~nm} \mathrm{Cr}$ puddles for contact by thermal evaporator followed by $30 \mathrm{~nm}$ of Au layer by sputtering at $2 \times 10^{-7}$ Torr and $4 \mathrm{mTorr}$ base and Ar pressure [24]. The thickness of $\mathrm{SiO}_{2}$ is $300 \mathrm{~nm}$ and the width and length of each FET unit is $90 \mu \mathrm{m}$ and $80 \mu \mathrm{m}$ respectively.

(a)
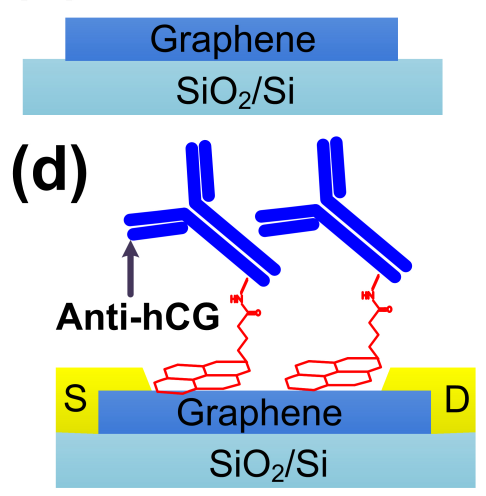

(e)

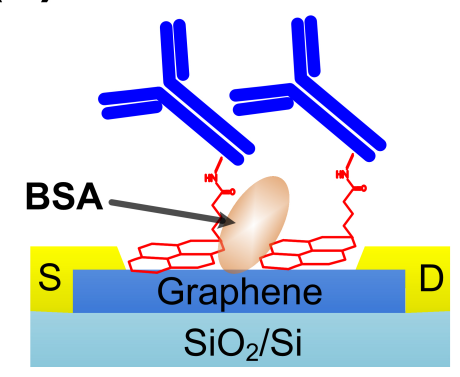

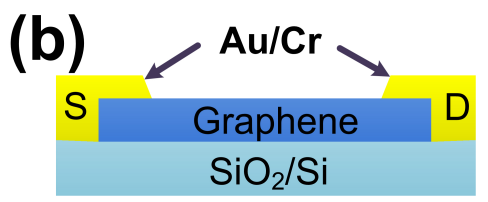

(c)
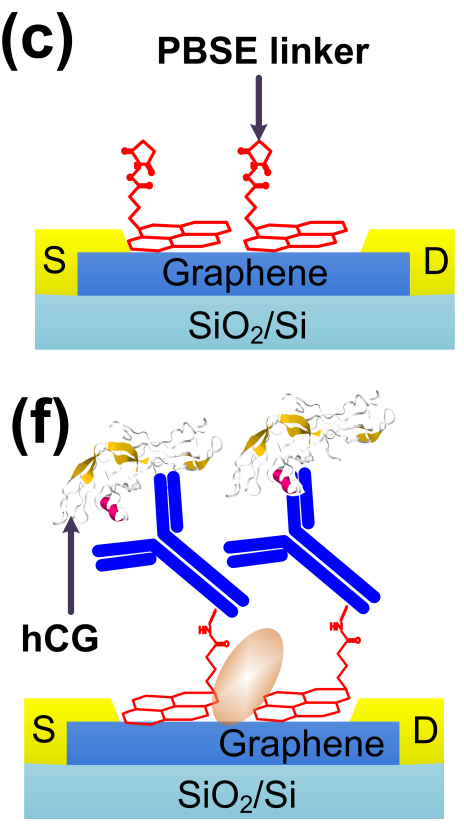

Figure 2. Schematic illustration of hCG biosensor fabrication. (a) monolayer graphene on $\mathrm{SiO}_{2} / \mathrm{Si}$ substrate; (b) Fabrication of BG-gFET; (c) anchoring of non-covalent linkers by $\pi-\pi$ bond; (d) immobilization of antibodies; (e) blocking by BSA; (f) binding of hCG antigen.

Pyr-NHS was used as the linker between graphene channel and anti-hCG via $\pi-\pi$ interaction. Consisting of hydrophobic pyrenyl moiety base and a bio-active ester head, Pyr-NHS does not require any pre-treatment of antigen with EDAC/NHS chemistry is required [14]. 2 mM Pyr-NHS solution was prepared by adding $0.0385 \mathrm{~g}$ Pyr-NHS powder into $5 \mathrm{~mL}$ methanol with modest shaking for $5 \mathrm{~h}$. The linker solution was drop-casted on BG-gFETs and sealed in a moist environment for $2 \mathrm{~h}$ at room temperature, followed by methanol rinsing to avoid passivation layer formation. The functionalized graphene channels were covered by $10 \mu \mathrm{g} \cdot \mathrm{mL}^{-1}$ anti-hCG solution and incubated at $4{ }^{\circ} \mathrm{C}$ for $4 \mathrm{~h}$. The surface of graphene channel was rinsed with PBS buffer and immersed in BSA solution with a concentration of $0.5 \mathrm{mg} \cdot \mathrm{mL}^{-1}$ to block the free amino groups to prevent the non-specific binding 
of hCG. Finally, hCG solution with concentrations ranging from $1 \mathrm{pg} \cdot \mathrm{mL}^{-1}$ to $100 \mathrm{ng} \cdot \mathrm{mL}^{-1}$ were prepared by diluting $1 \mu \mathrm{g} \cdot \mathrm{mL}^{-1}$ stock solution with PBS buffer and then incubated on graphene channel at $4{ }^{\circ} \mathrm{C}$ for $4 \mathrm{~h}$ to ensure the strong antibody/antigen binding. Finally, the samples were treated with $100 \mathrm{mM}$ ethnolamine for $30 \mathrm{~min}$ and washed with DIW for $5 \mathrm{~min}$ to remove non-specific passivation followed by vacuum dry at 30 Torr for an hour before characterization [25].

\section{Results and Discussion}

\subsection{Assessment of Surface Morphology}

The morphology of the samples and surface modification was characterized by Raman spectroscopy, XPS and cyclic voltammetry. Figure 3 shows raman maps of 2D/G for graphene $/ \mathrm{SiO}_{2}$ before and after adding linker and others. The intensity ratios of 2D-band to G-band are higher than 5. These data confirm that the transferred graphene before and after treating with linker and others is high-quality and continuous. For effective removal of photoresist during fabrication, deep UV (DUV) technique was used within the fabrication process to reduce photoresist contamination. The details of our work to obtain clean, uniform, and continuous graphene, with a typical low sheet resistance along with XPS and Cyclic voltammetry analysis have been elaborated in our recent works in detail $[19,23]$. The results demonstrated effective reduction of sheet resistance and contact resistance on the graphene surface by about $60 \%$ and $80 \%$, respectively. Electrical current transport characteristics also demonstrated minimizing this residue on the graphene surface giving less hysteresis of electronic transport in BG-gFETs.
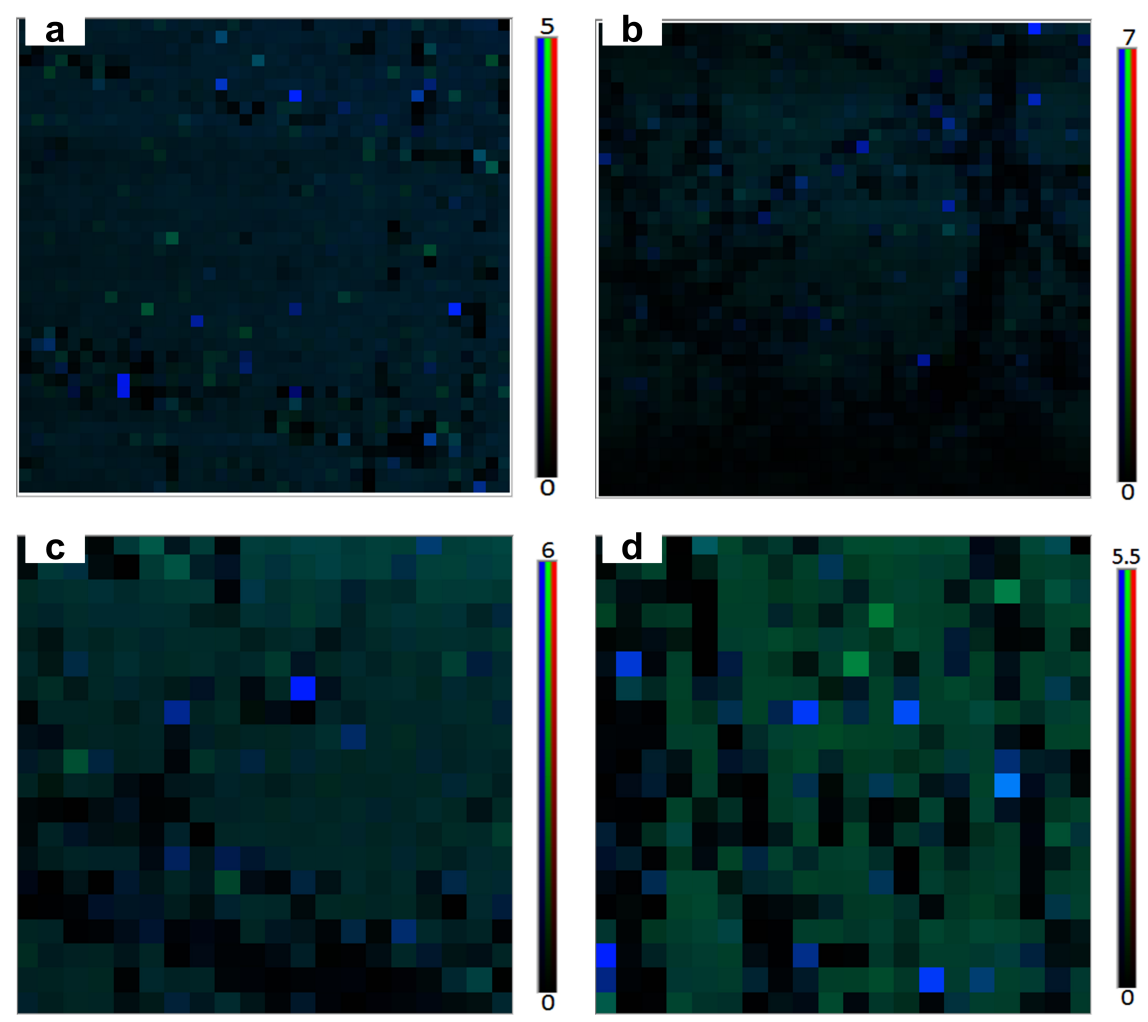

Figure 3. Raman maps of $2 \mathrm{D} / \mathrm{G}$ for (a) bare graphene $/ \mathrm{SiO}_{2} ;(\mathbf{b})$ linker + graphene $/ \mathrm{SiO}_{2} ;(\mathbf{c})$ anti-hCG + linker/graphene/SiO $2 ;(d) h C G+$ anti-hCG/linker/graphene/ $\mathrm{SiO}_{2}$.

\subsection{Qualitavie Assessment of Graphene and Surface Modification}

Raman spectroscopy was used to confirm the layer number of graphene film. In the Raman spectrum shown in Figure $4 \mathrm{a}$, the G-peak $\left(\sim 1600 \mathrm{~cm}^{-1}\right)$ and $2 \mathrm{D}$-peak $\left(\sim 2700 \mathrm{~cm}^{-1}\right)$ are clearly 
resolved with strong intensity and sharp shape of $2 \mathrm{D}$ peak, indicating that the graphene film is monolayer. To avoid possible surface contaminations, all devices were thermal-annealed ( $\mathrm{Ar}$ $1.5 \mathrm{ccm}$ and $\mathrm{H}_{2} 250 \mathrm{sccm}, 300 \mathrm{~K}$ ) before electrical measurements were performed. Figure $4 \mathrm{~b}$ presents the back gate $\left(\mathrm{V}_{\text {back.gate }}\right)$-dependent resistance measurement results of a typical graphene FET device, showing the ambipolar field-effect characteristics. Both the carrier type and density of graphene can be modulated by $\mathrm{V}_{\text {back.gate. The maximum resistance (or the minimal conductance) }}$ point corresponds to the charge neutrality point $V_{\mathrm{cnp}}$ (or the Dirac point in the case of monolayer graphene), indicating how the graphene film is intrinsically doped, i.e., $\mathrm{p} / \mathrm{n}$ doped when $\mathrm{V}_{\mathrm{cnp}}$ is positive/negative or non-doped when $\mathrm{V}_{\mathrm{cnp}}$ is equal to zero. For this particular device, $\mathrm{V}_{\mathrm{cnp}}$ is around $12 \mathrm{~V}$, suggesting it is intrinsically $\mathrm{p}$-doped. The $\mathrm{p}$-doping characteristics of graphene are usually caused by exposure to an oxygen-containing atmosphere, as oxygen molecules adsorbed onto defect or oxidized sites on a graphene surface will function as p-type dopants by trapping electrons during device fabrication process [26]. Several studies have shown that the conductance of graphene device exhibited ambipolar behavior and demonstrated better operating stability and higher sensing performance in the p-type region than in the n-type region $[27,28]$. The slight asymmetry around the Dirac point can be ascribed to the interaction of graphene with the contacts, as explained by Di Bartolomeo et al. [29,30].The feature of being sensitive to the surrounding environment renders graphene an ideal sensing material for detecting charged objects. With the presence of certain charged environment, the charge doping level (or Fermi level) of graphene will be changed, resulting in a shift of $\mathrm{V}_{\mathrm{cnp}}$ or the resistance- $\mathrm{V}_{\text {back.gate }}$ curve.

(a)

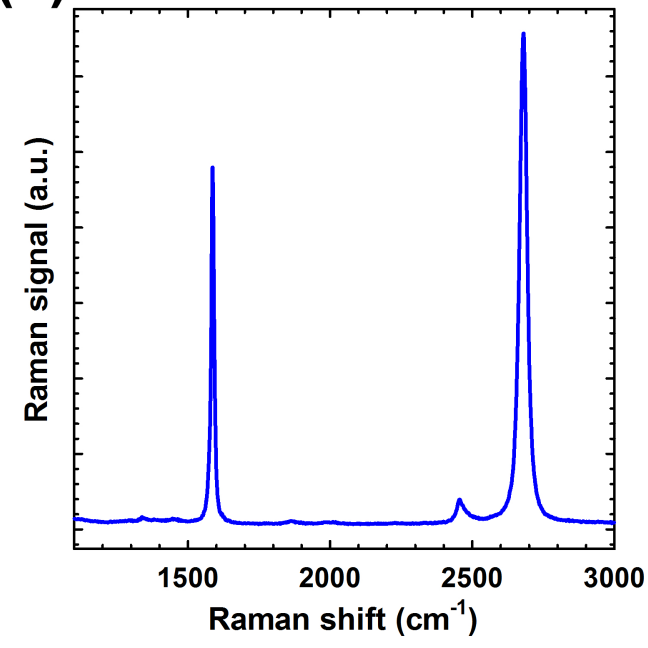

(b)

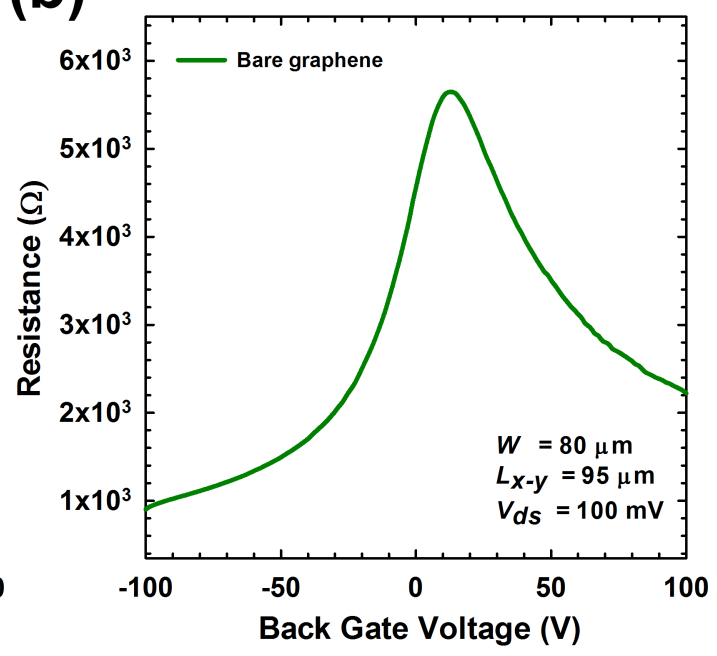

Figure 4. Raman characterization of patterned graphene channel (a) and resistance-back gate voltage curve of a typical graphene FET device $(\mathbf{b})$.

\subsection{Dependence of $h C G$ Concentration}

To examine the performance of bgFET immunosensor for detection, we performed a quantitative analysis on multiple BG-gFET devices to examine the change in resistance of the graphene channel after Ab-hCG binding ranging from $1 \mathrm{pg} \cdot \mathrm{mL}^{-1}$ to $100 \mathrm{ng} \cdot \mathrm{mL}^{-1}$. All the devices were formed by modification processes under controlled physiochemical conditions. We used $100 \mu \mathrm{g} \cdot \mathrm{L}^{-1} \mathrm{PBS}$ to obtain standard solutions with different concentrations. After adding standard solutions with different concentrations for four hours at $4{ }^{\circ} \mathrm{C}$ followed by washing with PBS and $\mathrm{N}_{2}$ drying, we measured the resistance- $\mathrm{V}_{\text {back.gate }}$ curves within $2 \mathrm{~min}$. The $\mathrm{pH}$ of standard solutions was kept at neutral to avoid false response. At least three replicates were conducted for each concentration and the relative standard deviations between replicates were 5-24\%, indicating good reproducibility 
of our measurement. The test results of standard solutions with five concentrations (i.e., $1 \mathrm{pg} \cdot \mathrm{mL}^{-1}$, $10 \mathrm{pg} \cdot \mathrm{mL}^{-1}, 100 \mathrm{pg} \cdot \mathrm{mL}^{-1}, 1 \mathrm{ng} \cdot \mathrm{mL}^{-1}, 100 \mathrm{ng} \cdot \mathrm{mL}^{-1}$ ) are shown in Figure 5a. Before adding solutions, the $\mathrm{V}_{\mathrm{cnp}}$ was around $12 \mathrm{~V}$, indicating the $\mathrm{p}$-doping nature of the device in dry state. After adding standard solution of $1 \mathrm{pg} \cdot \mathrm{mL}^{-1}$, we clearly observed right shifts of the curve, i.e., higher $V_{\mathrm{cnp}}$. For higher concentrations, the resistance- $V_{\text {back.gate }}$ shifted further right and $V_{c n p}$ became higher.
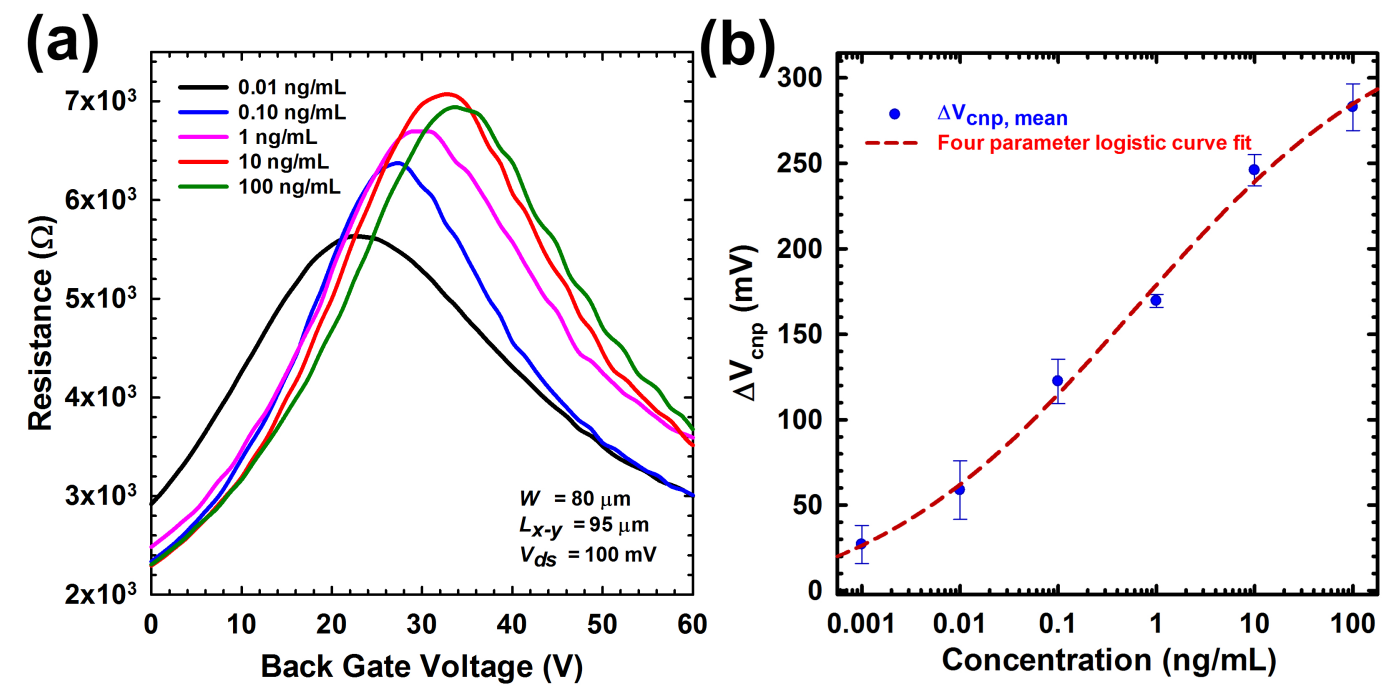

Figure 5. (a) The resistance- $V_{\text {back gate }}$ curves of five different $h C G$ concentrations $\left(1 \mathrm{pg} \cdot \mathrm{mL}^{-1} \sim 100 \mathrm{ng} \cdot \mathrm{mL}^{-1}\right)$. (b) The measured $\Delta \mathrm{V}_{\mathrm{cnp}}$ versus concentration (in semilog scale); The red dotted line corresponds to the fitting results by using a four parameter logistic function.

Such results indicate that our bgFET immunosensors are effective for detecting at different concentrations. The detection mechanism can be explained by a simple picture that, in dry condition, higher concentrations of hCG cause electron doping of the graphene (which is intrinsically p-doped) by approaching its surface, which leads to a right shift of the transfer curves or a higher $V_{\text {cnp }}$ [31] and potentially used as an effective parameter to characterize ion concentrations. We tested multiple devices with similar response observed. In Figure $5 b$, we plotted the measured $\Delta \mathrm{V}_{\text {cnp }}$ versus concentration (in logarithmic scale) of the tested standard solutions from three representative devices. A lognormal fitting was performed to obtain a calibration curve for quantification. Based on our measurement, the lowest concentration our graphene aptasensor detected was $1 \mathrm{pg} \cdot \mathrm{mL}^{-1}$, and a concentration-response calibration curve showed a good fitting $\left(R^{2}=0.97\right)$ in the range of concentration evaluated, which is advantageous for the detection of hCG having wide-ranging expression profiles in the different stages of diagnosis i.e., pregnancy or cancer development. The obtained limit of detection (LOD) was 600 times more sensitive than the one achieved with the previously published hCG biosensor on BG-gFET [15] and twenty times better than one obtained with polysilicon nanogap [32]. In addition, our biosensor was capable of clearly monitoring the anti-hCG + hCG interaction at concentration as low as $1 \mathrm{pg} \cdot \mathrm{mL}^{-1}$ directly without pre- or post-amplification process. This demonstrated that our aptasensor can work well for samples much lower than the safe level.

\subsection{Slectivity, Stability, Reproducibility and Reusability}

Selectivity tests were carried out by using interfering species, such as BSA, glucose, uric acid (UA), ascorbic acid (AA) and $1 \mathrm{pg} / \mathrm{mL}$ of hCG (Figure 6a). It can be observed that the response of interfering species on our BG-gFET is less than $40 \mathrm{mV}$ at the lowest concentration of hCG. In addition, the BG-gFETs showed satisfactory stability. After a month long storage, the resistance response decreased $21 \%$, which is due to the gradual deactivation of the immobilized biomolecules (Figure 6b). 
At present, the sensor is for one-time use only, however, to extend the BG-gFET sensor into practical reusable applications, further work is needed.
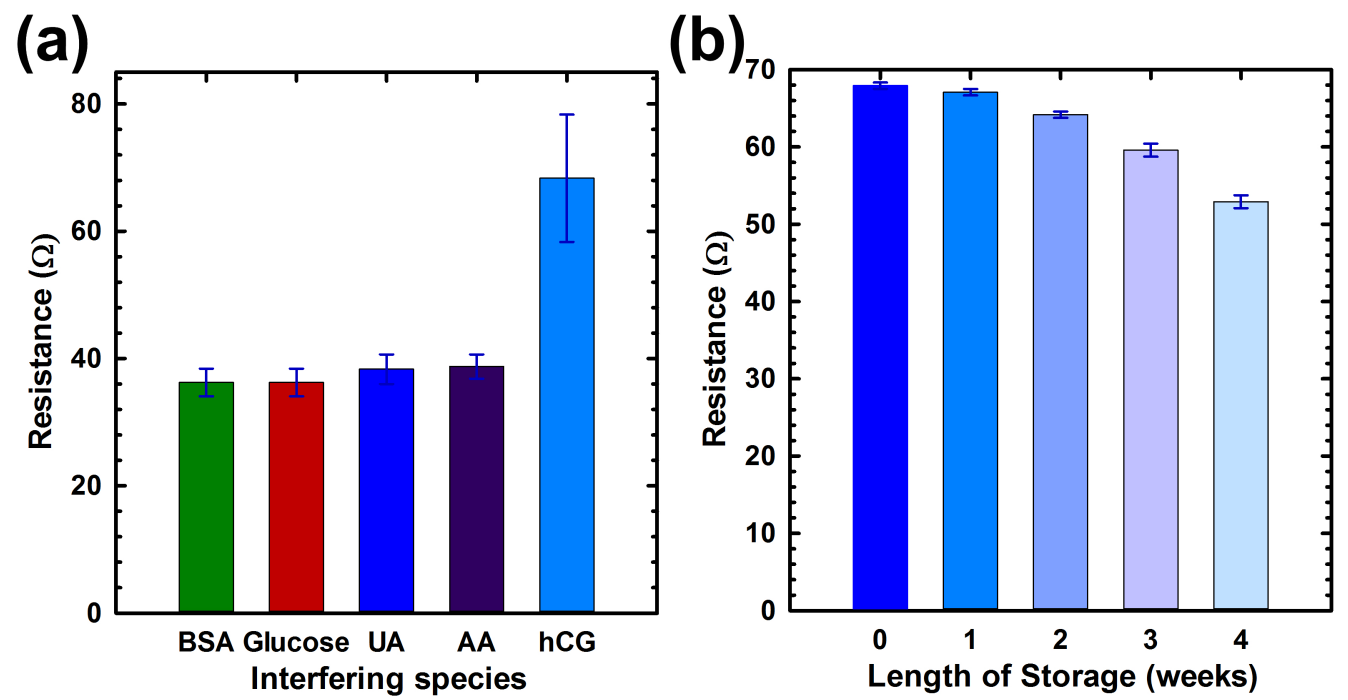

Figure 6. Selectivity and stability measurements for BG-gFET immunosensor. (a) The selectivity of the immunosensor with interfering species. BSA, Glucose (GLUC), Uric Acid (UA) and Ascorbic Acid (AA) were used; (b) long term stability of the biosensor for upto four weeks of storage.

\section{Conclusions}

In summary, we demonstrated a BG-gFET based immunosensor functionalized with a noncovalent linker for high sensitivity and label-free detection of hCG. The sensors showed the detection of hCG at concentration levels as low as $1 \mathrm{pg} \cdot \mathrm{mL}^{-1}$, which is much lower than the clinical limit $\left(5 \mathrm{ng} \cdot \mathrm{mL}^{-1}\right)$ with a broad dynamic range in concentration $\left(1 \mathrm{pg} \cdot \mathrm{mL}^{-1}\right.$ to $\left.100 \mathrm{ng} \cdot \mathrm{mL}^{-1}\right)$ [15]. Further development in multiple markers with a multiplex array is necessary for scalable and cost-effective detection. These results clearly show that BG-gFET immunosensors are promising devices for the use as label-free biological sensors that can electrically detect biomolecules.

Acknowledgments: We gratefully acknowledge financial support from the Engineering and Physical Sciences Research Council (EPSRC, Swindon, UK) through its Programme Grant scheme (Grant No. EP/M006301/1). We also acknowledge the technical support on annealing from Professor Guy's group at Swansea University and XPS from the National EPSRC XPS Users' Service (Newcastle University).

Author Contributions: K.I. and G.P. conceived and designed the experiments; K.I. performed the experiments; K.I. and A.S. analyzed the data; K.I. and G.P. contributed analysis tools; K.I. and G.P. co-wrote the paper.

Conflicts of Interest: The authors declare no conflict of interest.

\section{References}

1. Chetcuti, A.F.; Wong, D.K.; Stuart, M.C. An indirect perfluorosulfonated ionomer-coated electrochemical immunosensor for the detection of the protein human chorionic gonadotrophin. Anal. Chem. 1999, 71, 4088-4094. [CrossRef] [PubMed]

2. Stenman, U.-H.; Tiitinen, A.; Alfthan, H.; Valmu, L. The classification, functions and clinical use of different isoforms of HCG. Hum. Reprod. Update 2006, 12, 769-784. [CrossRef] [PubMed]

3. Chai, R.; Yuan, R.; Chai, Y.; Ou, C.; Cao, S.; Li, X. Amperometric immunosensors based on layer-by-layer assembly of gold nanoparticles and methylene blue on thiourea modified glassy carbon electrode for determination of human chorionic gonadotrophin. Talanta 2008, 74, 1330-1336. [CrossRef] [PubMed]

4. Zhang, B.; Mao, Q.; Zhang, X.; Jiang, T.; Chen, M.; Yu, F.; Fu, W. A novel piezoelectric quartz micro-array immunosensor based on self-assembled monolayer for determination of human chorionic gonadotropin. Biosens. Bioelectron. 2004, 19, 711-720. [CrossRef] 
5. Wang, J.; Yuan, R.; Chai, Y.; Cao, S.; Guan, S.; Fu, P.; Min, L. A novel immunosensor based on gold nanoparticles and poly-(2,6-pyridinediamine)/multiwall carbon nanotubes composite for immunoassay of human chorionic gonadotrophin. Biochem. Eng. J. 2010, 51, 95-101. [CrossRef]

6. Vartiainen, J.; Alfthan, H.; Lehtovirta, P.; Stenman, U.H. Elevated hCG and a high proportion of hCG $\beta$ in serum preceding the diagnosis of trophoblastic disease by seven months. BJOG Int. J. Obstet. Gynaecol. 2002, 109, 589-590. [CrossRef]

7. Wen, G.; Liang, X.; Liu, Q.; Liang, A.; Jiang, Z. A novel nanocatalytic sers detection of trace human chorionic gonadotropin using labeled-free vitoria blue $4 \mathrm{R}$ as molecular probe. Biosens. Bioelectron. 2016, 85, 450-456. [CrossRef] [PubMed]

8. Bergveld, P. Development, operation, and application of the ion-sensitive field-effect transistor as a tool for electrophysiology. IEEE Trans. Biomed. Eng. 1972, 342-351. [CrossRef] [PubMed]

9. De Moraes, A.C.M.; Kubota, L.T. Recent trends in field-effect transistors-based immunosensors. Chemosensors 2016, 4, 20. [CrossRef]

10. Novoselov, K.S.; Geim, A.K.; Morozov, S.V.; Jiang, D.; Zhang, Y.; Dubonos, S.V.; Grigorieva, I.V.; Firsov, A.A. Electric field effect in atomically thin carbon films. Science 2004, 306, 666-669. [CrossRef] [PubMed]

11. Pumera, M. Graphene in biosensing. Mater. Today 2011, 14, 308-315. [CrossRef]

12. Kuila, T.; Bose, S.; Khanra, P.; Mishra, A.K.; Kim, N.H.; Lee, J.H. Recent advances in graphene-based biosensors. Biosens. Bioelectron. 2011, 26, 4637-4648. [CrossRef] [PubMed]

13. Mohanty, N.; Berry, V. Graphene-based single-bacterium resolution biodevice and DNA transistor: Interfacing graphene derivatives with nanoscale and microscale biocomponents. Nano Lett. 2008, 8, 4469-4476. [CrossRef] [PubMed]

14. Liu, F.; Kim, Y.H.; Cheon, D.S.; Seo, T.S. Micropatterned reduced graphene oxide based field-effect transistor for real-time virus detection. Sens. Actuators B Chem. 2013, 186, 252-257. [CrossRef]

15. Teixeira, S.; Burwell, G.; Castaing, A.; Gonzalez, D.; Conlan, R.; Guy, O. Epitaxial graphene immunosensor for human chorionic gonadotropin. Sens. Actuators B Chem. 2014, 190, 723-729. [CrossRef]

16. Yeh, C.-H.; Kumar, V.; Moyano, D.R.; Wen, S.-H.; Parashar, V.; Hsiao, S.-H.; Srivastava, A.; Saxena, P.S.; Huang, K.-P.; Chang, C.-C.; et al. High-performance and high-sensitivity applications of graphene transistors with self-assembled monolayers. Biosens. Bioelectron. 2016, 77, 1008-1015. [CrossRef] [PubMed]

17. Ping, J.; Vishnubhotla, R.; Vrudhula, A.; Johnson, A.C. Scalable production of high-sensitivity, label-free DNA biosensors based on back-gated graphene field effect transistors. ACS Nano 2016, 10, 8700-8704. [CrossRef] [PubMed]

18. Gao, Z.; Kang, H.; Naylor, C.H.; Streller, F.; Ducos, P.; Serrano, M.D.; Ping, J.; Zauberman, J.; Carpick, R.W.; Wang, Y.-J.; et al. Scalable production of sensor arrays based on high-mobility hybrid graphene field effect transistors. ACS Appl. Mater. Interfaces 2016, 8, 27546-27552. [CrossRef] [PubMed]

19. Li, B.; Pan, G.; Suhail, A.; Islam, K.; Avent, N.; Davey, P. Deep UV hardening of photoresist for shaping of graphene and lift-off fabrication of back-gated field effect biosensors by ion-milling and sputter deposition. Carbon 2017, 118, 43-49. [CrossRef]

20. Li, X.; Cai, W.; An, J.; Kim, S.; Nah, J.; Yang, D.; Piner, R.; Velamakanni, A.; Jung, I.; Tutuc, E.; et al. Large-area synthesis of high-quality and uniform graphene films on copper foils. Science 2009, 324, 1312-1314. [CrossRef] [PubMed]

21. Suk, J.W.; Kitt, A.; Magnuson, C.W.; Hao, Y.; Ahmed, S.; An, J.; Swan, A.K.; Goldberg, B.B.; Ruoff, R.S. Transfer of CVD-grown monolayer graphene onto arbitrary substrates. ACS Nano 2011, 5, 6916-6924. [CrossRef] [PubMed]

22. Islam, K.; Chand, R.; Han, D.; Shin, I.-S.; Kim, Y.-S. An electrochemical assay for restriction endonuclease activity using graphene monolayer. J. Electrochem. Soc. 2014, 161, B261-B264. [CrossRef]

23. Suhail, A.; Islam, K.; Li, B.; Jenkins, D.; Pan, G. Reduction of polymer residue on wet-transferred cvd graphene surface by deep UV exposure. Appl. Phys. Lett. 2017, 110, 183103. [CrossRef]

24. Li, B.; Pan, G.; Jamil, N.Y.; Al Taan, L.; Awan, S.; Avent, N. Shielding technique for deposition of au electrical contacts on graphene by sputtering. J. Vac. Sci. Technol. A 2015, 33, 030601. [CrossRef]

25. Vuoriluoto, M.; Orelma, H.; Zhu, B.; Johansson, L.-S.; Rojas, O.J. Control of protein affinity of bioactive nanocellulose and passivation using engineered block and random copolymers. ACS Appl. Mater. Interfaces 2016, 8, 5668-5678. [CrossRef] [PubMed] 
26. Schedin, F.; Geim, A.; Morozov, S.; Hill, E.; Blake, P.; Katsnelson, M.; Novoselov, K. Detection of individual gas molecules adsorbed on graphene. Nat. Mater. 2007, 6, 652-655. [CrossRef] [PubMed]

27. Park, S.J.; Kwon, O.S.; Lee, S.H.; Song, H.S.; Park, T.H.; Jang, J. Ultrasensitive flexible graphene based field-effect transistor (fet)-type bioelectronic nose. Nano Lett. 2012, 12, 5082-5090. [CrossRef] [PubMed]

28. Kwon, O.S.; Park, S.J.; Hong, J.-Y.; Han, A.-R.; Lee, J.S.; Lee, J.S.; Oh, J.H.; Jang, J. Flexible fet-type vegf aptasensor based on nitrogen-doped graphene converted from conducting polymer. ACS Nano 2012, 6, 1486-1493. [CrossRef] [PubMed]

29. Di Bartolomeo, A.; Giubileo, F.; Romeo, F.; Sabatino, P.; Carapella, G.; Iemmo, L.; Schroeder, T.; Lupina, G. Graphene field effect transistors with niobium contacts and asymmetric transfer characteristics. Nanotechnology 2015, 26, 475202. [CrossRef] [PubMed]

30. Di Bartolomeo, A.; Santandrea, S.; Giubileo, F.; Romeo, F.; Petrosino, M.; Citro, R.; Barbara, P.; Lupina, G.; Schroeder, T.; Rubino, A. Effect of back-gate on contact resistance and on channel conductance in graphene-based field-effect transistors. Diam. Relat. Mater. 2013, 38, 19-23. [CrossRef]

31. Khan, M.F.; Iqbal, M.Z.; Iqbal, M.W.; Iermolenko, V.M.; Khalil, H.W.; Nam, J.; Kim, K.S.; Noh, H.; Eom, J. Stable and reversible doping of graphene by using KNO3 solution and photo-desorption current response. RSC Adv. 2015, 5, 50040-50046. [CrossRef]

32. Balakrishnan, S.; Hashim, U.; Gopinath, S.C.; Poopalan, P.; Ramayya, H.; Omar, M.I.; Haarindraprasad, R.; Veeradasan, P. A point-of-care immunosensor for human chorionic gonadotropin in clinical urine samples using a cuneated polysilicon nanogap lab-on-chip. PLoS ONE 2015, 10, e0137891. [CrossRef] [PubMed]

(C) 2017 by the authors. Licensee MDPI, Basel, Switzerland. This article is an open access article distributed under the terms and conditions of the Creative Commons Attribution (CC BY) license (http:// creativecommons.org/licenses/by/4.0/). 